O USO DE SIMULADORES DE MATERIAL DE LABORATÓRIO, EM ATIVIDADES DE EXPERIMENTAÇÃO INVESTIGATIVAS E LÚDICAS NO ENSINO MÉDIO

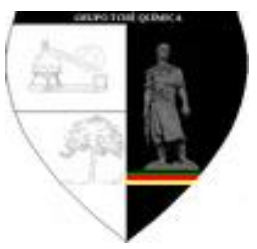

\title{
USE OF SIMULATORS FOR LABORATORY EQUIPMENT IN ACTIVITY OF INVESTIGATIVE PLAYFUL EXPERIMENTATION IN SECONDARY SCHOOLS
}

\author{
OLIVEIRA, N. ${ }^{1 *}$; BENEDETI, F. E. ${ }^{2}$; FIORUCCI, A. R. ${ }^{3} ;$ BENEDETTI, L. P. dos S. ${ }^{4}$; BELOTO, M. R. M. de O. ${ }^{5}$ \\ 1,2,3,4,Universidade Estadual de Mato Grosso do Sul - UEMS,Curso de Química, Cidade Universitária de Doura- \\ dos - Caixa postal 351 - CEP: 79804-970, Dourados - MS, Brasil \\ (fone: +55 673902 2651; fax: +55 673902 2364) \\ 1,2,3,5, Universidade Estadual de Mato Grosso do Sul - UEMS, CInAM, Cidade Universitária de Dourados - Caixa \\ postal 351 - CEP: 79804-970, Dourados - MS, Brasil \\ (fone: +55 673902 2652; fax: +55 673902 2364)
}

Received 07 January 2011; received in revised form 09 May 2011; accepted 2 July 2011

\section{RESUMO}

Este artigo relata a construção e o uso de simuladores de materiais de laboratório em atividades de experimentação simples, usando material e reagente alternativo que, além de não interferir residualmente no meio ambiente, não oferecem riscos aos alunos na sua manipulação, podendo essas atividades serem desenvolvidas, principalmente, em escolas que não contam com um laboratório. Os simuladores atenderam perfeitamente aos propósitos esperados nas atividades, demonstrando que podem vir a ser um excelente recurso didático. O tempo de 50 minutos foi suficiente para desenvolver cada atividade, sendo a sala de aula o espaço físico para a sua realização. A princípio foi apresentada uma situação problema para os alunos, que foram incentivados a formular e discutir suas hipóteses. No decorrer das atividades foi possível fazer com que os alunos pudessem desconstruir idéias de senso comum relacionados aos temas discutidos (ácido, base, separação de misturas, entre outros) reconstruindo-as a partir do senso científico. A reconstrução aconteceu em clima descontraído onde os erros foram corrigidos sem constrangimentos. Os significados não foram impostos e sim, negociados, construídos por todos. Alguns alunos reviram suas idéias iniciais - conhecimento equivocado que tinham sobre determinado fenômeno - acolhendo as idéias de outros alunos que melhor explicaram o fenômeno.

Palavras-chave: manipulação; conceito científico; fenômeno

\section{ABSTRACT}

This article relates the construction and the use of simulators of laboratory materials in activities of simple experimentation, using material and alternative reagent. Apart from not residually interfering with the environment, the manipulation of the aforementioned materials does not expose students to any risk. Thereby, such activities can be developed especially in those schools in which a laboratory is not available. The simulators perfectly responded to the expected purposes of the activities, demonstrating the possibility of becoming an excellent didactic resource. The 50 minutes period was enough to develop each individual activity; furthermore, the classroom was the physical space used for the execution of such activities. At the beginning, a study case was presented and students were encouraged to formulate and discuss their hypothesis. In the course of the activities, it was possible to bring students to deconstruct concepts of common sense related to the themes discussed - acid, base, separation of mixtures, amongst others - reconstructing them from the scientific sense. This reconstruction took place in a relaxed atmosphere in which mistakes were corrected without resulting in embarrassments. Meanings were not imposed; instead, they were built by all. Some students reconsidered their initial concepts - incorrect knowledge they had about a specific phenomenon welcoming the ideas from other students who were better able to explain such phenomenon.

Key words: manipulation; scientific concept; phenomenon

PERIÓDICO TCHÊ QUÍMICA • www.periodico.tchequimica.com • Vol. 8 N. 16. • ISSN 1806-0374 (impresso) • ISSN 1806-9827 (CD-ROM) • ISSN 2179-0302 (meio eletrônico) 


\section{INTRODUÇÃO}

A atividade de experimentação constituise numa das partes mais atrativas do ensino de Química. Para Giordan (1999) a experimentação desperta um forte interesse entre os alunos, tanto que os leva, ludicamente, a obter uma melhor compreensão dos temas trabalhados em sala de aula. Porém, as atividades de experimentação quando são realizadas nas escolas de Ensino Médio geralmente utilizam a característica aristotélica empirista, isto é, apresentam o objetivo de demonstrar, confirmar uma teoria ou lei sem predomínio do caráter investigativo. A formação de conceitos é caracterizada de uma maneira concreta, através de sensações e experimentação. Nas escolas, esses conceitos são transmitidos frequentemente de forma abstrata, em sentido vago, dificultando o seu aprendizado.

De acordo com Gil Pérez e Valdés Castro (1996) foram apontadas alternativas para que se possa realizar uma experimentação que incorpore vários aspectos da atividade científica para que ela deixe de ser uma atividade simplesmente demonstrativa e passe a ter características investigativas, com o que concordamos por acreditarmos que a experimentação investigativa permite que $\mathrm{o}$ aluno desenvolva capacidades intelectuais enquanto que a experimentação demonstrativa ou ilustrativa exercita quase que exclusivamente as capacidades de realização da prática e da observação.

Para melhor ilustrar a atividade de experimentação investigativa, faremos uso das palavras de Fiorentini (2004) usadas em relação à formação de futuros professores:

A experiência investigativa, (...) pode ser comparada a uma viagem na qual se sabe o ponto de partida, mas não se sabe o ponto de chegada. Representa, portanto, um empreendimento arriscado, uma aventura. É durante a viagem que acontece o processo formativo, pois à medida que vamos conhecendo fatos novos, também nos transformamos enquanto seres humanos ( $p, 245)$.

Autores como Gil Pérez e Valdés Castro (1996), Giordan (1999), Barros (2000), Campanário (2000) Figueiroa (2001), Leite (2001), Leite e Figueiroa (2004), entre outros, classificam a experimentação em dois tipos: experiências ilustra- tivas e experiências investigativas. Podemos acrescentar, ainda, as atividades de experimentação demonstrativas e as atividades de experimentação descritivas.

Segundo Oliveira (2009)(Tabela 1), existem quatro tipos de atividades de experimentação que constam da tabela extraída de seu trabalho.

Tabela 1 Tipos de atividades de experimentação

Experimentação Descrição

O professor é o experimentador e o sujeito principal. Cabe

Demonstrativa ao aluno a atenção e o conhecimento do material utilizado. O aluno observa, anota, desenha e classifica.

É realizada pelo aluno que manipula todo o material sob llustrativa a direção do professor. Serve para comprovar ou re/descobrir leis.

É realizada pelo aluno sob a Descritiva observação ou não do professor. O aluno entra em contato com o fenômeno.

É realizada pelo aluno que discute idéias, elabora hipóteses e usa da experimentação para compreender os fenômeInvestigativa nos que ocorrem. A participação do professor é dada na mediação do conhecimento. Serve para adquirir capacidade argumentativa.

A atividade de experimentação deve permitir ao aluno uma postura ativa, sendo ele estimulado a descobrir os conceitos que envolvam os fenômenos observados na atividade; assim, faz-se necessário que os alunos formulem e discutam hipóteses para chegarem à solução de problemas.

Poucos são os professores que realizam atividades de experimentação. Para Machado e Mol (2008), dentre outros motivos, "a falta de la- 
boratório também é alegação comum, mas se constata que a existência deste não garante a realização de atividades experimentais", com o que concordamos tendo em vista que: ou o professor não tem habilidade para a tarefa, ou não tem tempo para prepará-la, ou exige a presença de um técnico para executá-la, entre outros aspectos.

Considerando estes fatores, pensamos que a importância da atividade não está em quem vai prepará-la e sim, em quem irá dela participar. Assim, a participação ativa do aluno no desenvolvimento da atividade é de suma importância, ou seja, é nele que deve estar focado toda a observação e, é nesse momento que o professor passa a ser um mediador, com o objetivo de propiciar as discussões que levem à formulação de hipóteses e de suas reformulações, incentivando os alunos a compreenderem os conceitos envolvidos na atividade.

O uso de material alternativo constitui-se em mais um subsídio para o professor na realização de atividades de experimentação em sala de aula. $O$ professor pode utilizar protótipos/simuladores, construídos a partir de material alternativo, em atividades de experimentação, sem perda apreciável da qualidade dos resultados alcançados, desde que para fins didáticos. Dessa forma uma garrafa de Poli Tereftalato de Etileno (PET) serve para a construção de um protótipo/simulador de um funil de decantação; um béquer; com uma mangueira transparente interna, um condensador; dentre outras aplicações que pode ser usado em uma atividade de experimentação que permita melhorar a aprendizagem da Química ministrada no Ensino Médio.

Muitos pesquisadores têm desenvolvido propostas de atividades de experimentação com o uso de material alternativo (Valadares, 2001; Marconato et al., 2004; Teófilo et al., 2002; Oliveira e Soares, 2009; Simoni e Tubino, 2002; Guimarães et al., 2000).

A atribuição de novos significados, a relação das características lúdicas com a experimentação, proposta primordial deste trabalho, se revela nos Níveis de Interação Entre Jogo e Jogador, apresentados por Soares (2008) em seu livro, isto é, a manipulação efetiva de protótipos, de brinquedos, de materiais com novos significados.

A manipulação na construção e no uso de um simulador propicia momentos de ações cognitivas proporcionados pela imaginação e o en- cantamento, quando trabalhados em situações de atividades investigativas, sejam elas teóricas ou não. Dessa forma a manipulação que se faz presente nos jogos, não parece ser diferente do tipo de manipulação que se faz durante a experimentação. O brinquedo/simulador é manipulado da mesma forma e com os mesmos significados tanto no jogo quanto na experimentação. Tais formas consideram o cuidado, o carinho, entre outras relações específicas de aspectos do manuseio (Oliveira e Soares, 2009).

Segundo Oliveira e Soares (2009), a manipulação do material de laboratório, seja equipamento ou reagente, é que torna a atividade interessante ao aluno. Quando realizada com material alternativo o aluno se sente como se estivesse "brincando", momento em que está dando uma nova significação ao objeto que tem em suas mãos.

Durante a manipulação do material alternativo que fazem parte do seu cotidiano, o aluno se apropria de conceitos abstratos. Por exemplo, um objeto só é considerado grande se comparado com outros menores. A partir da compreensão de conceitos de tamanho, forma, cor, espessura é que ele vai desenvolvendo seu raciocínio lógico, o mesmo para o conceito de sólido, líquido e gasoso e, na atividade descrita nesse artigo, os conceitos de ácido, base e neutralização.

Conhecendo as qualidades dos objetos, e das substâncias, o aluno começa a compará-los e assim os relacionam com os diversos materiais ou reagentes de laboratórios com os quais já teve contato visual, em livros didáticos, diversas mídias, revistas, jornais, laboratórios de ciências da escola (quando existente) entre outros, passando a construir os conceitos científicos sobre os mesmos. Portanto, o material alternativo (equipamento ou substâncias) possibilita uma efetiva manipulação pelo aluno, além de propiciar, no caso proposto, a construção da bureta alternativa e o uso de substância ácidas e básicas do seu cotidiano.

Vários pesquisadores creditam que o aluno gosta da atividade de experimentação por que ela é divertida. Na realidade, observamos que a atividade de experimentação não é divertida por si só, a diversão está na manipulação do brinquedo que é o simulador e que se assemelha ao equipamento ausente com o qual o aluno realiza a atividade. $O$ equipamento/brinquedo é uma criação do aluno, quando construído com material alternativo ou com material de baixo custo. É o aluno quem dá ao brinquedo as funções que ele 
necessita que o brinquedo desenvolva durante a tarefa. É também a atitude lúdica que proporciona certo grau de ludicidade à atividade de experimentação. Se a atividade de experimentação for tediosa, ela ainda pode ser salva pela atitude lúdica, tanto do aluno, quanto do professor.

Outra importância na construção e manipulação de um simulador está na sua funcionalidade. $O$ aluno precisa trabalhar os seus conhecimentos teóricos para garantir que ele funcione. A participação do aluno é a parte mais importante dessa atividade; é na sua realização pelos alunos que haverá a manipulação e a discussão dos fenômenos que ocorrem durante a atividade. Sem a sua interação os conceitos químicos ficam mais difíceis de serem trabalhados. O aluno pode anotar todas as observações quando não participa ativamente da atividade, mas, não saberá explicar os conceitos ali envolvidos.

Segundo Piaget (1975), a manipulação de objetos pode trazer habilidades manuais aos aprendizes que se relacionam com sua estrutura de aprendizado. Por isso, quando insistimos na manipulação, o fazemos por dois aspectos: 1) aumenta-se sobremaneira o ludismo e a ludicidade da atividade; 2) desenvolve-se a habilidade manual do aprendiz. A consequência é o aumento do interesse, o que traz motivação e facilita o desenvolvimento de aspectos cognitivos. Se a atividade de experimentação é realizada pelo professor ou técnico de laboratório (demonstrativa) ou ainda por um aluno seguindo um roteiro pré-estabelecido (ilustrativa) na qual o material de laboratório já se encontra pronto para ser usado, não há a manipulação (interação com o equipamento/brinquedo) ou a construção desse material, então não ocorre a ludicidade.

Nota-se novamente, a questão relacionada ao primeiro e terceiro níveis de interação, segundo Soares (2008), o que nos leva a acreditar que a ludicidade está fortemente ligada à manipulação que os alunos fazem na construção, montagem e utilização dos objetos nas atividades de experimentação, sejam eles alternativos ou não.

Outro aspecto presente nas atividades que tem estreita relação com os jogos é a própria manipulação do equipamento pelos alunos. Alguns têm mais facilidades de manuseio do que outros, o que não impede a interação no grupo. No manuseio de brinquedos em situações de jogo, tais comportamentos também são observados, onde algumas crianças e adolescentes apresentam mais habilidades manuais do que outras (Chateau, 1987).

A reação de um ácido e uma base é um procedimento realizado principalmente para classificar os diferentes tipos de sais, no caso o sal neutro. É um procedimento relativamente simples que pode ser empregado no ensino médio para contextualizar análises químicas realizadas em laboratórios para controle de qualidade. Nesse procedimento o uso de indicadores é importante para se observar, através da mudança de cor, o momento em que se chega à neutralização do ácido ou da base. O indicador é composto por um par ácido/base conjugado cujo ácido apresenta uma coloração e a base outra. Este indicador deve possuir uma coloração intensa para uma das espécies, a fim de facilitar a visualização em soluções diluídas.

Experimentalmente, uma titulação volumétrica consiste em acrescentar lenta e progressivamente, com o uso de uma bureta, uma solução de concentração conhecida de ácido ou base a uma solução de concentração desconhecida (de base ou ácido), detectando com a variação da coloração de um indicador o ponto de neutralização. $\mathrm{O}$ pH ou $\mathrm{pOH}$, próximo ao ponto de equivalência muda rapidamente com a adição de pequenas quantidades de titulante; assim, uma nítida mudança de cor fornece uma indicação clara do ponto de equivalência (Silva, 2001). De tal forma, a mesma atividade serve para demonstrar a formação de um sal neutro, o que foi feito na sala de aula com os alunos utilizando-se reagentes alternativos (vinagre e solução de cal) e material alternativo na construção da bureta, suporte universal e béquer.

\section{MÉTODOS:}

O trabalho foi realizado nas escolas estaduais "Vilmar Vieira Matos" e "Antonio da Silveira Capilé" na cidade de Dourados-MS e teve a participação de cerca de 270 alunos de diferentes séries e períodos, do ensino médio.

Para garantir a análise que conduziriam as discussões no sentido de se obter os resultados e a elaboração de nossos resultados e de nossas conclusões, todas as atividades foram filmadas, além de serem realizadas as devidas anotações em diário de campo.

Ao entrar na sala de aula, o mediador colocou sobre a mesa do professor uma caixa contendo vários apetrechos, tais como: mangueiras, arames, garrafas, copos, barbante, seringas hipodérmicas, balões de festa, pregos, martelo, ali- 
cate, tesoura, massa epóxi, vinagre, cal, madeira, entre outros. A seguir, pediu aos alunos a formação de grupos de 4 (quatro) participantes, em torno de 2 (duas) carteiras. Os alunos agruparam-se segundo suas preferências, sem a intervenção do mediador.

Ao início da atividade de neutralização, o mediador solicitou que os alunos falassem o que sabiam sobre ácidos, bases e o tema "neutralização". Os alunos, em seus grupos, ou entre os demais grupos elaboraram e discutiram vários significados e teorias do que entendiam sobre o assunto, bem como apresentaram vários exemplos de ácidos e bases, inclusive alguns presentes no seu cotidiano. Ao que foi perguntado: Como proceder para realizar a neutralização de um determinado ácido ou base? Qual o material necessário para a sua realização? É possível a realização com material e reagente alternativos? Durante as discussões que aconteceram, os questionamentos feitos pelos alunos foram respondidos com outros questionamentos no sentido de que eles formulassem e discutissem novas hipóteses que resolvessem as questões propostas.

O método aplicado (situação problema), leva em consideração as palavras Libâneo ao citar que:

"O professor não apenas transmite uma informação ou faz perguntas, mas também ouve os alunos. Deve dar-lhes atenção e cuidar para que aprendam a expressar-se, a expor opiniões e dar respostas. O trabaIho docente nunca é unidirecional. As respostas e as opiniões dos alunos mostram como eles estão reagindo à atuação do professor, às dificuldades que encontram na assimilação dos conhecimentos. Servem também para diagnosticar as causas que dão origem a essas dificuldades." (1994, p.250)

Ao final da discussão, foi apresentado aos alunos uma solução de hidróxido de cálcio, $\mathrm{Ca}(\mathrm{OH})_{2}$, obtida pela mistura de uma colher de cal viva, adquirida em lojas de material de construção, adicionada em dois litros de água, e, uma solução ácida obtida a partir do vinagre caseiro incolor, no caso, o vinagre de álcool.

A definição, o processo de neutralização, bem como o material de laboratório para os procedimentos foram propostas que surgiram durante as discussões que se constituíram como parte da estratégia a que chegaram os alunos. Com a proposta do uso de um indicador para a neutralização, fez-se o seguinte questionamento: Qual a

função do indicador na estequiometria da reação de neutralização? Nova discussão é estimulada pelo mediador e os alunos chegam a conclusão que devem usar um indicador para o ácido ou para a base para controlar o momento em que acontece a neutralização (viragem). $O$ indicador apontado pelos alunos foi a fenolftaleína. O mediador aceita e pergunta: como proceder ao experimento?

Foi usado como equipamento o material construído anteriormente, na atividade de separação da mistura de água e óleo, o balão de decantação, pelo fato de os alunos encontrarem algumas similaridades entre o balão de decantação e a bureta, provavelmente por ambas terem o controle de vazão de líquidos. A figura 1 ilustra o desenvolvimento da atividade de neutralização executada pelos alunos.

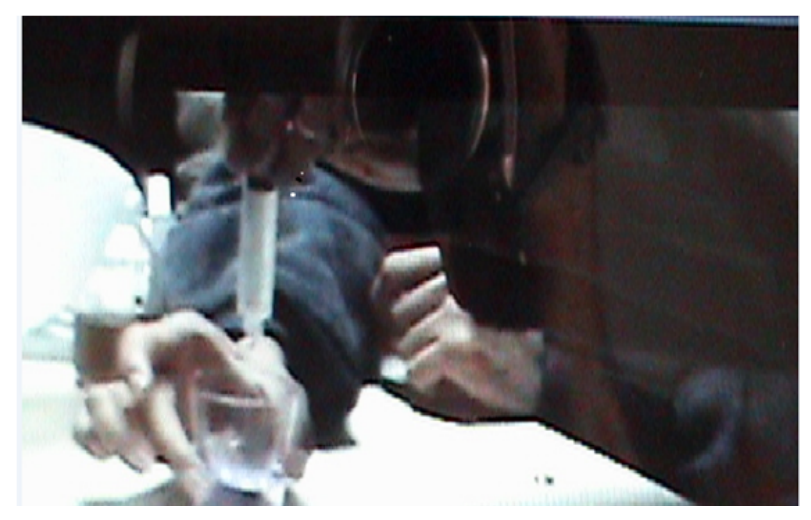

Figura 1. Atividade de neutralização.

A atribuição de novos significados aos objetos com os quais o aluno interage tem relação com objetos vistos anteriormente. Os alunos atribuem aos simuladores a serem construídos ou utilizados as mesmas propriedades ou funções dos equipamentos já vistos ou utilizados (Soares, 2008).

Ao final da atividade, os alunos perguntaram se a neutralização era o mesmo que a titulação. Foi esclarecido que não. Para a titulação, os resultados careceriam de precisão em suas medidas volumétricas, daí o uso da bureta, simulada pelo equipamento utilizado por eles, e o conhecimento de uma das concentrações. Para a neutralização, não se teve a preocupação quanto às concentrações e nem com as medidas de volumes utilizadas na reação.

\section{MATERIAIS:}

PERIÓDICO TCHÊ QUÍMICA • www.periodico.tchequimica.com • Vol. 8 N. 16. - ISSN 1806-0374 (impresso) • ISSN 1806-9827 (CD-ROM) • ISSN 2179-0302 (meio eletrônico) 
- Estilete

- Caneta Pilot - Marcador Permanente Ponta Média $2.0 \mathrm{~mm}$.

- Mangueira de plástico transparente com $1 \mathrm{~cm}$ de diâmetro interno e $60 \mathrm{~cm}$ de comprimento;

- Madeiras para construção do simulador do suporte universal;

- Fio de cobre (100 cm de comprimento) para a construção do suporte;

- Conjunto "equipo de soro" de uso médico-hospitalar, utilizado na aplicação de soro, via endovenosa;

- Copos plásticos transparentes $200 \mathrm{~mL}$ (de preferência o mais rígido possível);

- Seringa hipodérmica de 1, 5, 10 e de $20 \mathrm{~mL}$;

- Cola tipo massa epoxi;

- Solução de vinagre branco comercial;

- Cal "virgem" ou "viva" encontrado em casa de material de construção;

- Solução indicadora de fenolftaleína (o extrato de repolho roxo pode ser utilizado como indicador alternativo).

\section{PROCEDIMENTOS}

Preparação da solução de cal $\left[\mathrm{Ca}(\mathrm{OH})_{2}\right]$, hidróxido de cálcio:

Em uma garrafa PET transparente de volume igual a dois litros, contendo cerca do volume da garrafa, adicionou-se 1 colher de sopa cheia de cal. A seguir, a garrafa, depois de tampada, foi agitada para que a cal adicionada se dissolvesse. Pela decantação, separou-se a solução de cal obtida (parte incolor da mistura) da cal sedimentada.

Preparação da solução indicadora de fenolftaleína:

Em um copo contendo $100 \mathrm{~mL}$ de álcool etílico a $96^{\circ} \mathrm{GL}$ (o volume de álcool pode ser obtido através de uma seringa hipodérmica), adicionou-se $1 \mathrm{~g}$ de fenolftaleína. A solução foi agitada por cerca de cinco minutos. Se, após a decantação, a solução apresentar sedimentos, deve ser feita a sua filtração. A solução deve ser acondicionada em um frasco (opaco) com conta-gotas e conservada em lugar fresco, de preferência na geladeira.

Preparação da solução indicadora alternativa (extrato de repolho roxo):
Colocou-se cerca de quatro folhas de repolho roxo em uma vasilha adicionando-se água até cobri-las. A seguir, a vasilha foi levada ao fogo até que a fervura reduziu o volume de água à metade do volume inicial. Após o seu resfriamento, a solução foi passada por um coador (filtro de papel usado para coar café, por exemplo) e guardada na geladeira até a sua utilização. De preferência, a solução de repolho roxo deve ser feita pouco tempo antes de ser usada. Ela se deteriora em cerca de dois a três dias.

\section{Montagem do suporte universal alternativo:}

Com o fio de cobre $(100 \mathrm{~cm})$, foi feito um aro com cerca de $10 \mathrm{~cm}$ de diâmetro que foi fixado, com o uso de pregos ou grampos, a um pedaço de madeira de medidas $20 \mathrm{~cm} \times 20 \mathrm{~cm} \times 1$ $\mathrm{cm}$. Segurando-se o aro fixo na madeira, o restante do fio de cobre foi levantado em um ângulo de $90^{\circ}$ (noventa graus) (Figura 2).

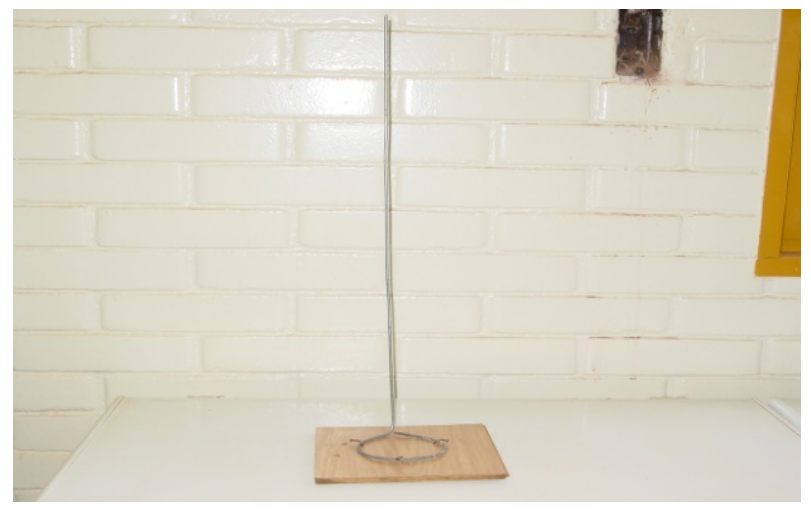

Figura 2. Suporte universal alternativo.

Montagem da bureta alternativa:

A seringa de $5 \mathrm{~mL}$ foi cortada a $1 \mathrm{~cm}$ acima da parte debaixo onde se encaixa a agulha (Figura 3). 


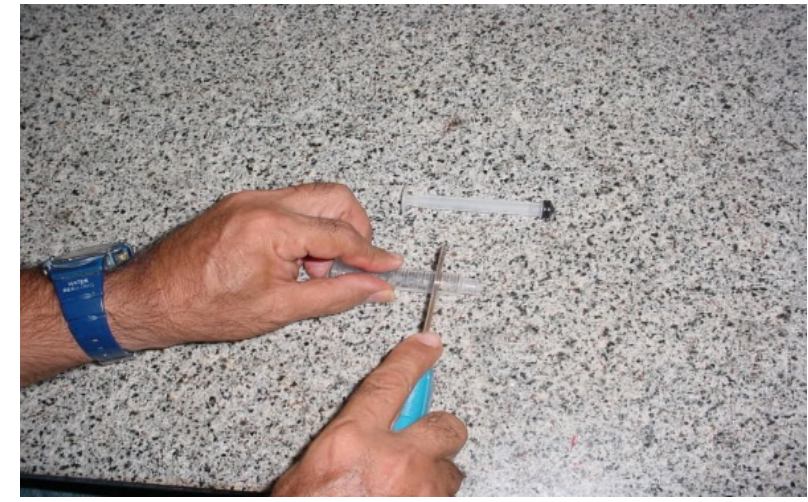

Figura 3. Cortando a seringa.

A mangueira de plástico transparente com $1 \mathrm{~cm}$ de diâmetro interno e $60 \mathrm{~cm}$ de comprimento foi colada no interior da parte menor da seringa que foi cortada (Figura 4).

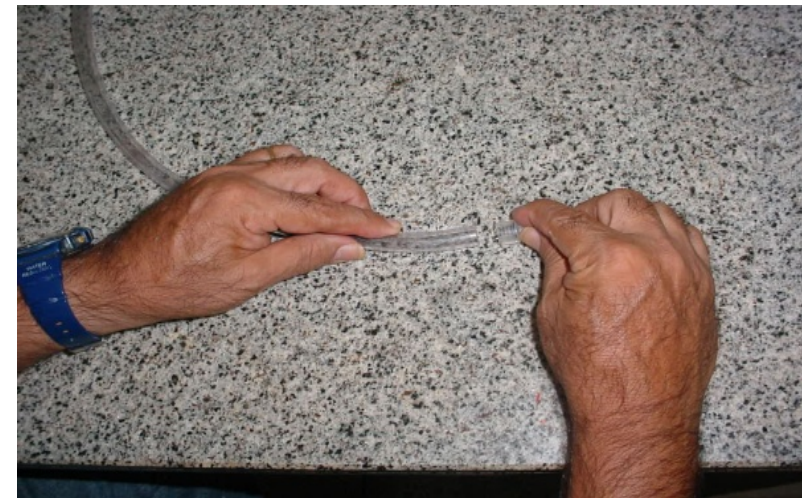

Figura 4. Colando a mangueira à seringa

A mangueira do equipo de soro foi cortada próxima a entrada do controlador da vazão, e fixada na ponta da seringa que foi cortada na etapa anterior. O tamanho da mangueira, a partir da saída do controlador de vazão deve ter cerca de $5 \mathrm{~cm}$. (Figura 5 )

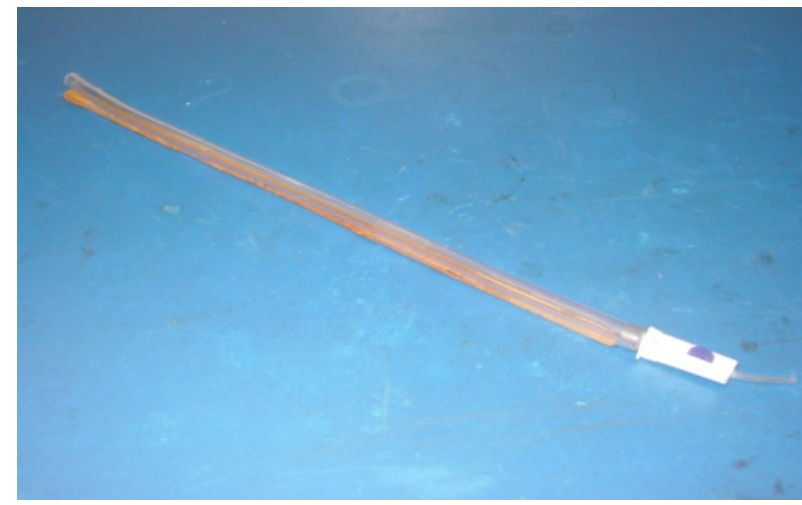

Figura 5. Colagem do equipo de soro.
A bureta alternativa foi fixada ao suporte confeccionado e, com o uso da seringa de $1 \mathrm{~mL}$, adicionou-se partes iguais de $1 \mathrm{~mL}$ de água, marcando-se na bureta o volume indicado em cada adição. Ao final, enumerou-se, a partir da base para o alto da bureta, os números de 50 a 0 .

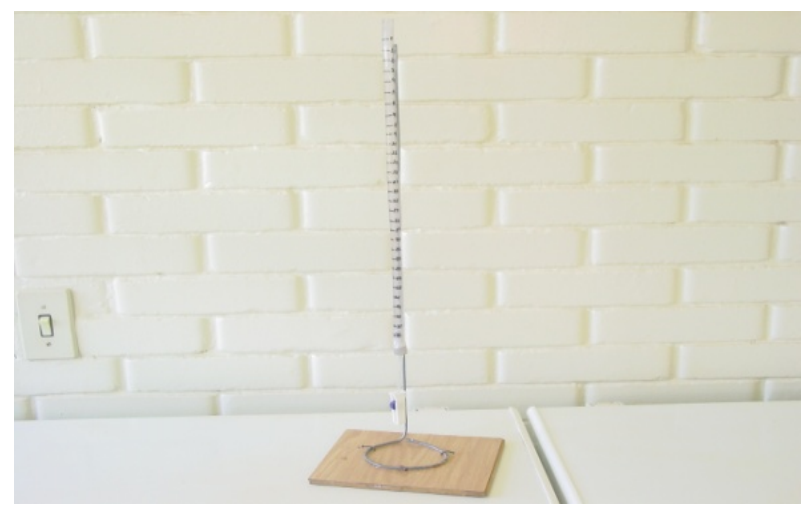

Figura 6. Bureta alternativa.

\section{f) Montagem do béquer alternativo:}

Para a graduação do copo de plástico transparente, simulador do béquer, procedeu-se da mesma forma que se procedeu para a graduação da bureta, usando-se, agora, a seringa de $10 \mathrm{~mL}$.

\section{DESENVOLVIMENTO DA ATIVIDADE:}

\section{Reação de Neutralização do vinagre com solução de $\mathrm{Ca}(\mathrm{OH})_{2}$ :}

Para a reação de neutralização propostas pelos alunos, foram adotados, a partir das discussões, os seguintes procedimentos:

- a bureta foi fixada ao suporte universal previamente confeccionado (figura 6).

- Foi adicionado à bureta $50 \mathrm{~mL}$ de vinagre.

- No béquer foram adicionados $30 \mathrm{~mL}$ da solução de hidróxido de cálcio.

- No béquer foram adicionadas 20 gotas de indicador, no caso a fenolftaleína, que apresentou a cor rósea.

- Para dar inicio à reação, foi aberta a vazão da bureta, deixando-se cair sobre a solução de hidróxido, no béquer, o vinagre contido na bureta.

- O béquer foi agitado até a "viragem" (ponto final da reação que fica próximo ao ponto de 
equivalência em que o $\mathrm{pH}=7$ ), mudança da cor rósea no béquer para a incolor. Obtendose o sal acetato de cálcio, proveniente da reação do ácido acético $\left(\mathrm{CH}_{3} \mathrm{COOH}\right)$ contido no vinagre $+\mathrm{Ca}(\mathrm{OH})_{2}$ (proveniente da solução de cal), de acordo com a equação abaixo:

$$
2 \mathrm{CH}_{3} \mathrm{COOH}+\mathrm{Ca}(\mathrm{OH})_{2} \rightarrow \mathrm{Ca}\left(\mathrm{CH}_{3} \mathrm{COO}\right)_{2}+2 \mathrm{H}_{2} \mathrm{O}
$$

\section{RESULTADOS E DISCUSSÃO:}

$\mathrm{Na}$ análise das filmagens foram observados os seguintes diálogos, logo após os alunos serem questionados de como procederiam para processar a neutralização:

Aluna 1: "mistura ué, é só misturar e pronto"; "isso mesmo". Mediador: A mistura ficará neutra? Alunos: "Vai ué, quando mistura ácido e base, não dá sal e água?"..., "é!!!", "porque?", "sei não como é que a gente vai saber se não está ácido ou base", "é mesmo!!!"

(Filme 171 (04:56 a 14:43)

Alunos: "coloca o indicador na base, ela fica rosa. Depois pinga o ácido na base até ela ficar branca", "e como vamos parar de pingar o ácido?", "é só usar o negocinho que nós usou na decantação, fecha a torneirinha e pronto". A analogia feita pelos alunos refere-se ao balão de decantação que eles montaram para a separação da mistura de água e óleo, trabalhada anteriormente em outro momento

(Filme 171 (17:56 a 22:03)

Alunos: "olha que legal está ficando cor-derosa!!!", "é parece que um fiozinho rosa está descendo na água"... "olha, olha ficou branco", "fecha, fecha", "professor, professor acabou".

(Filme 172 (12:56 a 14:33)

Ao final da atividade alguns alunos perguntaram se a reação de neutralização era o mesmo que titulação. Após algumas discussões e formulação de hipóteses feitas pelos alunos ficou claro que para a titulação os resultados careceriam de precisão em suas medidas volumétricas, daí o uso da bureta, simulada pelo equipamento utilizado por eles, e o conhecimento de uma das concentrações. Para a neutralização não se teve a preocupação quanto às concentrações e nem com as medidas de volumes utilizadas na reação, ficando claro que com o conhecimento da quantidade de ácido acético contido no vinagre, pode-se encontrar a concentração da solução de hidróxido de cálcio usada na atividade.

Na discussão da mudança de cor do indicador, foram feitos, ainda, mais dois questionamentos aos alunos: Qual a diferença entre o ponto de equivalência e o de viragem? Qual é o valor estipulado pela legislação brasileira para a concentração de ácido acético no vinagre? Nas discussões que se seguiram ficou esclarecido o conceito de ponto de equivalência e a zona de viragem de um determinado indicador e, também, que os indicadores têm faixas de viragem específicas e que diferem do ponto de equivalência, porém estão próximas a este.

\section{CONCLUSÕES:}

Da discussão dos resultados, concluiu-se que a utilização de materiais alternativos em atividades de experimentação, como a reação de neutralização do ácido acético presente no vinagre, pelo hidróxido de cálcio, na solução de água de cal, é um experimento passível de execução no Ensino Médio, obtendo-se bons resultados, já que, posteriormente, no laboratório da UEMS, a reação de neutralização dos reagentes alternativos utilizados foi realizada com material técnico de laboratório, suporte universal, bureta de 50 $\mathrm{mL}$ e béquer de $250 \mathrm{~mL}$ e não foram observados, macroscopicamente, resultados diferentes.

Na questão pedagógica, a atividade de experimentação, quando investigativa, é de grande valia para a construção coletiva dos conceitos que envolvem os fenômenos observados. A atividade é precedida de questionamento e não por roteiros ou procedimentos experimentais. Os conceitos de senso comum, como os observados durante a formulação e discussão das hipóteses para as respostas aos questionamentos do mediador relacionados aos conceitos de separação de misturas, ácido, base, neutralização, indicador, entre outros, observados também nos diálogos transcritos nos resultados e discussões, são desconstruídos sem constrangimentos sendo, em seguida, reconstruídos cientificamente, pelos demais alunos. Os significados/conceitos não são impostos e sim, negociados, construídos por todos.

$\mathrm{Na}$ atividade de experimentação investigativa o aluno é estimulado a propor soluções, procedimentos, definir conceitos, entre outras ações. Ao final da atividade os alunos não des- 
crevem apenas o roteiro e os fenômenos que ocorrem. Eles vão além, são capazes de explicar os fenômenos observados.

É importante que o professor discuta com seus alunos que os simuladores confeccionados como a bureta, por exemplo, podem ter o seu uso em atividades de ensino. Para outras atividades, o ideal deve ser o uso do material técnico que são mais confiáveis em termos de exatidão e reprodutibilidade.

\section{AGRADECIMENTOS:}

Às Escolas Estaduais "Vilmar Vieira Matos" e "Antonio da Silveira Capilé" e aos seus alunos na participação das atividades realizadas no projeto. À Universidade Estadual de Mato Grosso do Sul - UEMS e ao Conselho Nacional de Desenvolvimento Científico e Tecnológico - CNPq pela bolsa PIBIC/UEMS/CNPq.

\section{REFERÊNCIAS}

1. BARROS, S. G. (2000). Qué hacemos habitualmente em las actividades prácticas? Como podemos mejoralas. En M. SEQUEIRA, L. DOURADO, M. T. VILAÇA, J. L.SILVA, A. S. AFONSO y J. M. BAPTISTA (Orgs.). Trabalho prático e experimental na educação em ciências. Braga: Universidade do Minho.

2. CAMPANÁRIO, Juan Miguel El desarrollo de la metacognición en el aprendizaje de las ciencias: Estrategias para el profesor $y$ actividades orientadas al alumno. Enseñanza de las Ciencias. (2000)

3. FIGUEIROA, A. (2001). Actividades laboratoriais e educação em ciências: Um estudo com manuais escolares de ciências da natureza do $5^{\circ}$ ano de escolaridade e respectivos autores. Tese (mestrado) Universidade do Minho, Braga.

4. CHATEAU, Jean. O jogo e a criança, São Paulo, Ed Summus, 1987.

5. FIORENTINI, Dario. A Didática e a Prática de Ensino mediadas pela investigação sobre a prática. In ROMANOWSKI, Joana; MARTINS, Pura Lucia O.; JUNQUEIRA, Sérgio R.A. (Orgs.). Conhecimento Local e Conhecimento Universal: pesquisa, didática e ação docente. Curitiba: Champagnat. 2004, p.243-257.

6. GIL-PÉREZ, D. \& VALDÉS CASTRO, P. La Orientación de las Prácticas de
Laboratorio como Investigación: Un Exemplo llustrativo. Enseñanza de las Ciências, vol. 14, n 2, 1996, .p. 155-163.

7. GIORDAN, M. O papel da Experimentação no ensino de ciências. Química Nova na Escola, n. 10, p. 43-49, 1999

8. GUIMARÃES, P. I. C.; OLIVEIRA, R. E. C. e ABREU, R. G. de. Extraindo óleos essenciais de plantas. Química Nova na Escola, n. 11, p. 45-46, 2000.

9. LEITE, L. (2001). Contributos para uma utilização mais fundamentada do trabalho laboratorial no ensino das ciências. En Cadernos Didácticos de Ciências, Volume 1.Lisboa: Ministério da Educação, Departamento do Ensino Secundário.

10. LEITE, L.; FIGUEIROA, A. (2004). Las actividades de laboratorio y la explicación científica en los manuales escolares de ciencias. Alambique - Didáctica de las Ciencias Experimentales, 39, pp. 20-30.

11. LIBÂNEO, J. C.. Didática. São Paulo: Cortez, 1994.

12. MACHADO Patrícia F. L. \& MOL, G. S., Experimentando química com segurança, Rev. Química Nova na Escola N²7, p.5760,fev/2008

13. MARCONATO, J. C.; FRANCHETTI, S. M. M. \& PEDRO, R. J. Solução-tampão: uma proposta experimental usando materiais de baixo custo. Química Nova na Escola, n. 20, p. 59-62, 2004.

14. OLIVEIRA, N. 2009. Atividades de Experimentação Investigativas Lúdicas no Ensino de Química: Um estudo de caso. Tese (doutorado em Química) - Universidade Federal de Goiás, Goiânia - GO, $147 \mathrm{p}$.

15. OLIVEIRA, N. e SOARES, M. H. F. B. As atividades de experimentação e suas interações com a ludicidade. Ciência e Educação, submetido, 2009.

16. PIAGET, Jean. A Formação do Símbolo na Criança: imitação, jogo e sonho, imagem e representação. Tradução: Álvaro Cabral e Cristiano Monteiro Oiticica. $2^{a}$ edição. RJ: Zahar, 1975.

17. SILVA, E. O. Explorando as bases matemáticas da volumetria: uma proposta didática. Química Nova na Escola, n. 13, p. 13-17, 2001.

18. SIMONI, J. A. e TUBINO, M. Chafariz de amônia com materiais do dia-a-dia: uma

PERIÓDICO TCHÊ QUÍMICA • www.periodico.tchequimica.com • Vol. 8 N. 16. - ISSN 1806-0374 (impresso) • ISSN 1806-9827 (CD-ROM) • ISSN 2179-0302 (meio eletrônico) 
causa inicial... Quantos efeitos? Química Nova na Escola, n. 16, p. 45-49, 2002.

19. SOARES, M.H.F.B. Jogos para o Ensino de Química. Ed.Ex Libris. Guarapari - ES. 2008.

20. TEÓFILO, R. F.; BRAATHEN, P. C. \& RUBINGER, M. M. M. Reação relógio iodeto/iodo com material alternativo de baixo custo e fácil aquisição. Química Nova na Escola, n. 16, p. 41-44, 2002.

21. VALADARES, E. C. Propostas de experimentos de baixo custo centradas no aluno e na comunidade. Química Nova na Escola, n. 13, p. 38-40, 2001.

\section{Para saber mais}

1. SOUZA, M. P.; MERÇON, F.; SANTOS, N.; REPELLO, C. N. \& AYRES, A. C. S. Titulando 2004: um software para o ensino de Química. Química Nova na Escola, n. 22, p. 35-37, 2005.

2. A respeito da legislação que regula a produção e comercialização de vinagre (Lei $n^{\circ} 5.823$, de 14 de novembro de 1972), acessar o endereço: http://e-legis.bvs.br/leisref/ public/showAct.php?id=189 